\title{
Birleșik Arap Emirlikleri'nde Kültürel Miras ve Müzeler
}

\author{
Ceren KARADENİ*
}

Özet

Birleşik Arap Emirlikleri (BAE), Arap Körfezi’nde ve Orta Doğu'da sanat, kültür ve miras çalışmalarıyla adından söz ettiren ülkelerin başında gelmekte ve bu bağlamda Arap Dünyasının sanat ve kültür ağının merkezi olmayı hedeflemektedir. Kültürel miras ve müzecilik çalışmalarına 1969'da başlayan BAE, hızla artan göçmen nüfusuyla çokuluslu bir ülke haline gelmiş ve yerel kültürü korumak ve geliştirmek adına ulusal kültürü inşa etme sürecinde Emirileştirme poltikasını hayata geçirerek 1969'da başlayan müzecilik çalışmalarına müze çeşitliliğini artırarak devam etmiştir. Bu amaçla, uzun vadede petrol gelirlerine bağımlılığını azaltmak için kültürel miras yönetimi ve kültür turizmi alanındaki yatırımlarını artıran ülkede son 50 yılda öncelikle Al Ain ve Dubai Emirlikleri’nde ulusal müzeler açılmış; arkeolojik kazılar başlatılmış, yeni arkeoloji müzeleri inşa edilmiş; yaşayan müzeler ve miras köyleri oluşturulmuş, çocuk ve kadın kültürü, İslam Sanatı, çağdaş sanat ve sinema tarihi gibi konulara odaklanan yeni müzeler izleyicileriyle buluşmuştur. BAE müzecilik sektöründeki atılımlarını 2017 sonlarında açılan Abu Dhabi Louvre Müzesi ve yakın gelecekte açılması planlanan Zayed Ulusal Müzesi, Guggenheim Müzesi ve Dubai Gelecek Müzesi ile sürdürmeyi planlamaktadır.

BAE'deki “Emirileştirme” programına bağlı ulus inşasından hareketle, ülkenin çokuluslu yapısını gözler önüne serecek ve uluslararası kültür arenasında görünürlüğü artıracak müzeler kurma sürecinde izlediği müzecilik yaklaşımlarını ülkedeki müze çeşitliliği bağlamında değerlendirmeyi amaçlayan bu çalışmada ulusal müzelerin tarihi ve ülkedeki müze çeşitliliği bağlamında tartışılmış, BAE kültür politikalarının uygulanma biçimine ilişkin eleştiriler Louvre Abu Dhabi Müzesi üzerinden paylaşılmıştır.

Anahtar Sözcükler: Müzecilik, kültürel miras, müze eğitimi, Birleşik Arap Emirlikleri, Louvre Abu Dhabi.

\section{Cultural Heritage and Museums in United Arabian Emirates}

\section{Abstract}

The United Arab Emirates (UAE) is at the forefront of the Arabian Gulf and Middle Eastern countries in the fields of art, culture and heritage, and aims to be the hub of the Arab world's arts and culture network. Beginning from 1969 with cultural heritage and museum studies, the BAE has become a multinational country with a rapidly growing immigrant population and has continued to increase its museum diversity through museum studies with the process of building national culture in order to preserve and develop local cultural dynamics. UAE started its museological studies in 1969 to develop national culture and to pass on various exhibitions for various ages and interest groups. Over 50 years, Al Ain and Dubai Emirates have opened national museums emphasizing archeological excavations; archaeological museums have been built, heritage villages have been created and dozens of museums have been met with a focus on topics such as women's culture, numismatics, Islamic art, contemporary art and history of cinema etc. UAE plans to continue its breakthroughs in museum industry with the opening of Louvre Abu Dhabi in 2017 and with the upcoming openings of the Guggenheim Museum and Museum of Future in Dubai. In this study, cultural heritage studies of the seven emirates are evaluated in the context of museum diversity. The study aims to evaluate the museum approaches that the country follows throughout the process of establishing museums that will display the multinational structure of the country and increase her visibility in international arena with the act of the "Emiratization" program in UAE. The purpose is to evaluate the abovementioned museum approaches in the context of museum diversity. BAE culture is discussed in the context of the history of the national museums and the museum diversity in the country and cultural policies are criticized via sharing the shortcomings of the Louvre Abu Dhabi Museum.

Keywords: Museum studies, cultural heritage, museum education, United Arabian Emirates, Louvre Abu Dhabi. 


\section{Giriş}

1971'den önce ekonomisi ağırlıklı olarak balıkçılık ve inci ticaretine dayanan Birleşik Arap Emirlikleri (BAE) 1971'den sonra yeni petrol kaynaklarının keşfiyle birlikte dünya petrol rezervlerinin yüzde yedisine sahip bir federasyon devlet haline gelmiştir. Petrol rezervlerinin keşfi BAE'nin ekonomik anlamda hızla gelişmesini sağlarken aynı zamanda ülkeyi çokuluslu bir nüfus yapısıyla ve petrole dayalı ekonomiyi sürdürme problemleriyle de karşı karşıya getirmiştir (Davidson, 2009:16). Nüfusun yüzde 60,2'sini göçmenlerin oluşturduğu (United Nations, Department of Economic and Social Affairs, 2017) BAE'de meydana gelen çokuluslu demografik yapı yabancıların ezici çoğunluğa sahip olması nedeniyle toplumda kaygılara yol açmış, ulusal kültürün korunması ve geliştirilmesi için yerel nüfusun artırılması ve ulus inşası gibi ulusal politikaları gündeme getirmiştir. Bu politikalar doğrultusunda 2013'te “Emirileştirme” programı başlamış ve program 2015'in en çok üzerinde durulan iç siyaset konusu olmuştur (Üçağaç, 2015:233; Ghobash, 2012:59; Al Ali, 2015:26). Bununla birlikte 2006'dan bu yana petrol fiyatlarında yaşanan dalgalanmadan etkilenen BAE'nin, diğer Kuzey Afrika - Ortadoğu Körfez ülkeleriyle birlikte (Umman, Katar, Kuveyt vb.) petrole dayalı ekonomisini son yirmi yılda kalkınma politikaları doğrultusunda turizm sektörünü hareketlendirerek çekim merkezi haline gelmek amacıyla çeşitlendirmeye çalıştığı da izlenmektedir (Hacıoğlu ve Saylan, 2014:57).

BAE'nin bölgenin önemli ekonomik güçleri arasında yer alan Katar, Kuveyt ve Umman gibi uzun vadede petrol gelirlerine olan bağımlılığını azaltmak için turizmin önemini kavraması, kültür ve eğlence turizmiyle ekonomisini çeşitlendirme ihtiyacı duymasıyla birlikte özellikle Dubai, Ortadoğu'nun ticaret, turizm ve finans merkezi olarak öne çıkmıştır (Akbay, 2013:88). Dolayısıyla Ataman ve Demir'e (2012:5) göre Körfez monarşileri bölgede etkili olan Arap Baharı sürecinden olumsuz yönde etkilenirken BAE ile Katar siyasi olarak süreçten daha az etkilenmiş, turizm yatırımlarıyla karlı çıkan ülkeler arasında yer almışlardır. Arap Baharı öncesinde Dubai'nin başı çektiği BAE'de turist sayısının 2000-2010 yılları arasında 3 milyon 907 bin kişiden yedi milyon 432 bin kişiye (WT0,2001, s.10; WT0,2011, s.11), 2016 yılında ise 16 milyon 38 kişiye yükseldiği izlenmiştir (WT0,2016, s.12) ${ }^{1}$. Kocalar (2016:121), 2014'te BAE'de yatırımların \%16'sının turizm alanında gerçekleşmesini bu durumun gelecekteki yatırımların hangi alanlarda şekilleneceğini gösterdiğini ifade ederken Dünya Seyahat ve Turizm Konseyi (World Travel and Tourism Council) 2017 raporu $^{2}$, turizm gelirlerinin gayri safi yurt içi hasılaya \%12 katkı sağladığını gözler önüne sermektedir (Travel \& Tourism Economic Impact 2017 United Arab Emirates, 2017:3). Bouchenaki ve Kreps'e (2016:15) göre Arap Körfezinde turizmi geliştirmek amacıyla atılan en önemli adım son yirmi yılda başta Abu Dhabi, Dubai, Doha, Kuveyt, Manama, Muskat, Riyad ve Sharjah gibi şehirler olmak üzere çok sayıda yerleşim merkezinde müze sayısının ve çeşitliliğinin artırılmasıdır.

BAE ekonomisinin sürdürülebilirliğinin sağlanması için petrole bağımlılığın turizm aracılığıyla azaltılması hedeflenirken ulusal kültürün inşasını destekleyecek, göçmenlerden kaynaklanan çokkültürlü yapıyı gözler önüne serecek ve ulusal kültürün yanısıra evrensel kültürü temsil edecek ilgi çekici marka müzelerin kurulması kültür ve turizm sektörlerinin güçlendirilmesine yönelik yatırım kararları arasında öne çıkmaktadır (Mustafa, 2010:49; Picton, 2010:83; Al Ali, 2015:26; Jasim, 2008:366). Bu çalışmada BAE'deki “Emirileştirme” programına bağlı ulus inşasından hareketle ülkenin çokuluslu yapısını gözler önüne serecek ve uluslararası kültür arenasında tanınırlığını artıracak müzeler kurma sürecinde izlediği müzecilik yaklaşımlarını ülkedeki müze çeşitliliği bağlamında değerlendirmek amaçlanmıştır.

\section{Yöntem}

BAE'deki “Emirileştirme” programına bağlı ulus inşasından hareketle ülkenin çokuluslu yapısını gözler önüne serecek ve uluslararası kültür arenasında tanınırlığını artıracak müzeler kurma sürecinde izlediği müzecilik yaklaşımlarını ülkedeki müze çeşitliliği bağlamında değerlendirmeyi amaçlayan bu çalışma, betimsel tarama modelli olup veriler doküman inceleme tekniğiyle toplanmıştır. Nitel araştırmada doğrudan gözlem ve görüşmenin olanaklı olmadığı durumlarda veya araştırmanın geçerliğini arttırmak amacıyla, çalışılan araştırma problemiyle ilişkili yazılı ve görsel materyal ve malzemeler de araştırmaya dahil edilebilir. Doküman incelemesinde temel amaç, araştırılması hedeflenen olgu veya olgular hakkında bilgi içeren yazılı materyallerin analiz edilmesidir (Yıldırım ve Şimşek, 2006). Çalışmada doküman inceleme bağlamında McDonald (1998:4) ve Mason (2006:28) tarafindan da vurgulanan "müzeye bir metin olarak yaklaşma" yöntemi benimsenmiştir. Bu yaklaşımda müze vb. kültür kurumlarına ilişkin özellikler bir metin olarak ele alınarak okunmakta; müzenin 
yorum ve anlatım biçimleri, müzecilik felsefeleri ve stratejileri, sergi tasarım elemanları (etiketleme, aydınlatma) ve iç-dış mimari özellikleri bağlamında bütüncül olarak değerlendirilmektedir.

\section{Bulgular ve Yorum}

Arap Körfezi'ndeki kültürel miras ve müzecilik çalışmalarında ilk hareketlenme 1980 'lerde UNESCO, ICOM ve ICCROM tarafından bölgede yürütülen projelerle Kuveyt'te başlamıştır. 1983'te Kuveyt'te mimar Michel Ecochard'a tasarlatılan Ulusal Müze'nin ve 1988'de Bahreyn Krallığı'nda Danimarkalı mimari firması KHR Arkitekter tarafından tasarlanan Ulusal Müze'nin ziyarete açılması ilk girişimler olarak kabul edilmektedir. Arap Körfezi'ndeki bu girişimler aynı zamanda 1990'ların başındaki sanat alanındaki küresel gelişmeleri bu şehirlerine taşıma motivasyonuna bağlanmaktadır (Mejeher-Atassi ve Schwartz, 2012:11). BAE'de ise kültürel miras, sanat ve eğitim çalışmaları 1972'de sonradan Kültür ve Bilgi Gelişimi Bakanlığı adını alacak Bilgi ve Kültür Bakanlığı'nın kurulmasıyla başlamıştır. BAE ile yurtdışındaki kültür kurumları arasında koordinasyonu sağlamakla görevli Bakanlık, BAE ulusal kimliğini, mirasını ve Arap dilini korumakla ve gençlerin kültürel, sanatsal, sportif gelişim süreçlerine sponsor olmakla yükümlüdür ve yedi emirlikte merkezi kültür politikasına bağlı ancak birbirinden bağımsız çalışan kültür birimlerine liderlik etmektedir (United Arab Emirates Ministry of Culture and Knowledge Development, 2017). Bakanlığın teşvikiyle BAE mirasını korumakla yükümlü olarak BAE Miras Kulübü, BAE Dalış Topluluğu, Geleneksel Mirasının Yeniden Birleşmesi Derneği ile Belge, Arşiv ve Araştırma Merkezi'nin kurulması 2006 yılı itibarıyla BAE'de somut ve somut olmayan kültürel mirasını korumak, yeniden canlandırmak, teşvik etmek ve iyileştirmek amacıyla miras köylerinin oluşturulması, çağdaş müzecilik yaklaşımlarından hareketle yeni koleksiyonların oluşturulması, ulusal ve uluslararası çok sayıda sanat galerisinin kurulması sürecini hızlandırmıştır. Bu süreçte BAE'de kurulan ilk müzeler tarih ve arkeoloji koleksiyonlarını geleneksel müzecilik yaklaşımı doğrultusunda korumayı ve ulus inşası sürecine katkı sağlamak amacıyla sergilemeyi amaçlamıştır. Bu bağlamda BAE'nin ilk müzeleri ulusal kimliğin iki biçimde öne çıkarıldığı kurumlar olarak göze çarpmıştır: tarihsel koşullarla desteklenen müzeler ve topluluk kimliğini öne çıkaran müzeler (bir grubun parçası olarak kendini hisseden insanların kimliğine vurgu yapan müzeler) (Watson, 2007: 268; Picton, 2010:81). Ancak son yirmi yılda bu iki müze yaklaşımının ötesinde çağdaş sanattan doğa tarihine, sinema tarihinden paraya kadar çeşitli koleksiyon içeriklerine sahip "yeni müzeler" ortaya çıkmıştır (Bouchenaki, 2013:94).

Disiplinlerarası müzecilik araştırmaları ulus inşa etme ile ulusal müzelerin kurulması arasında yakın bir ilişki olduğuna dikkat çekmektedir (Knell, 2011:7). Lorch’a (2015) göre müzeler gelişmiş ülkelerin sahip olmaları gereken statülerden biridir. Ulusal müzeler oluşturulan koleksiyonu ulusun inşasında etkin biçimde kullanırlar. Bu müzeler geçmişi iyileştirir, canlandırır ve yeniden yorumlarlar; bir bölge, bir toplum ve bir kültür gibi homojen etnik kimlikleri görünür ve sürdürülür kılarlar. Dolayısıyla baskın kültürün sosyal, politik, etnik ve dini özelliklerini yansıtırlar (Bouquet; 2012:36; Preziosi, 2011:56). BAE'nin ilk idari merkezi olan Al Ain aynı zamanda ülkedeki ulusal müzelerin de ilk kurulduğu yerleşim yeridir. Neolitik Dönem'den beri (M.0̈.2500) yerleşim yeri olan Al Ain'de Hafit ve Hili Bölgelerinde dairesel taş mezarlar, su kuyuları, çok sayıda kerpiç yapı (konutlar, kuleler vb), şehir merkezinde emirlerin tarihi sarayları ve idari binalar bulunmaktadır. Tarihi kentteki yapıların Emirileştirme sürecinde ulusal kültürün inşasında önem arz etmesi müzeleştirme kapsamına alınmalarını hızlandırmış; 2011'de Al Ain'deki Hafit, Hili, Bidaa Bint Saud antik yerleşim merkezleri ve vaha alanları (Oasis) ile 2011'de UNESCO Dünya Kültürel Miras listesine girmesi bölgeyi ülkü turizminde görünür kılmıştır. Öte yandan Al Ain UNESCO Kültürel Miras Listesi alanları prehistorik ve protojenik kültürlerin izleriyle bedevi kültürünün devamlılığını yansıtması bakımından ulusal kültürün merkezi olarak tanımlanmıştır. Bu tanımlamayla birlikte 1969 'da Prehistorik Dönemden bu yana BAE'nin arkeolojik zenginliklerini araştırmak, ulusal kültürel mirası korumak ve çağdaş yöntemlerle sergileme motivasyonuyla Al Ain'de Al Ain Ulusal Müzesi kurulmuştur. Sultan Bin Zayed Kalesi'nde kurulan Al Ain Ulusal Müzesi, BAE'nin arkeolojik ve etnografik ulusal kültürel mirasını sergileyen geleneksel müzelerin başında gelmektedir. Müze özellikle Dünya Kültürel Miras Listesi'ndeki Hili Antik Kentine ilişkin arkeolojik çalışmaları ve eserleri deneysel yöntemlerle sergilemektedir (Al Nayadi, 2013:28). Ulusal Müzenin ardından 1855'den beri kullanımda olan ve BAE devlet başkanı Şeyh Khalifa'nın doğduğu ve 1946-1966 yılları arasında yaşadığı yer olan Qasr Al Muwaji (Al Muwaji Köşkü) restore edilerek müze haline getirilmiştir. Geleneksel Arap mimarisinin önemli bir örneği olan müze, şeyh ve aile- 
sinin gündelik yaşamını yansıtır. Her iki müzede de Prager’in (2015:25) vurguladığı statik müze sunumu kullanılmıştır.

Prager (2015:25), BAE'nin Al Ain'de kurulan sembol ulusal müzelerinde ve diğer Emirliklerdeki müzelerde sergileme ve sunumda iki yaklaşımın dikkat çektiğini vurgular: statik ve dinamik sunumlar. Statik sunum, koleksiyonun kronolojik bir yaklaşımla sergilendiği ve manken vb. yardımcı sergi malzemeleriyle desteklendiği sunum biçimidir. Prager dinamik sunumlara ulusal müzelerden ziyade, Abu Dhabi ve Dubai'de açılan yeni müzelerde rastlandığını vurgulamaktadır. Abu Dhabi Turizm ve Kültür Birimi şehirdeki müzelerde arşiv ve koleksiyon sergisi görünümünde statik sunumu benimsemesine rağmen ulusal müzelerin okul dışı öğrenme ortamları olarak “eğitim” işleviyle öne çıkmasını sağlamak amacıyla, petrol öncesi geleneksel döneme ilişkin eğitim etkinlikleri içeren ve farklı yaş grupları için müze binalarının tarihini yansıtarak koleksiyonu kronolojik olarak tanıtan eğitim kitapçıkları hazırlamıştır (Al Ain Palace Museum Activity Guide, 2016); Al Jahili Fort Activity Guide, 2016).

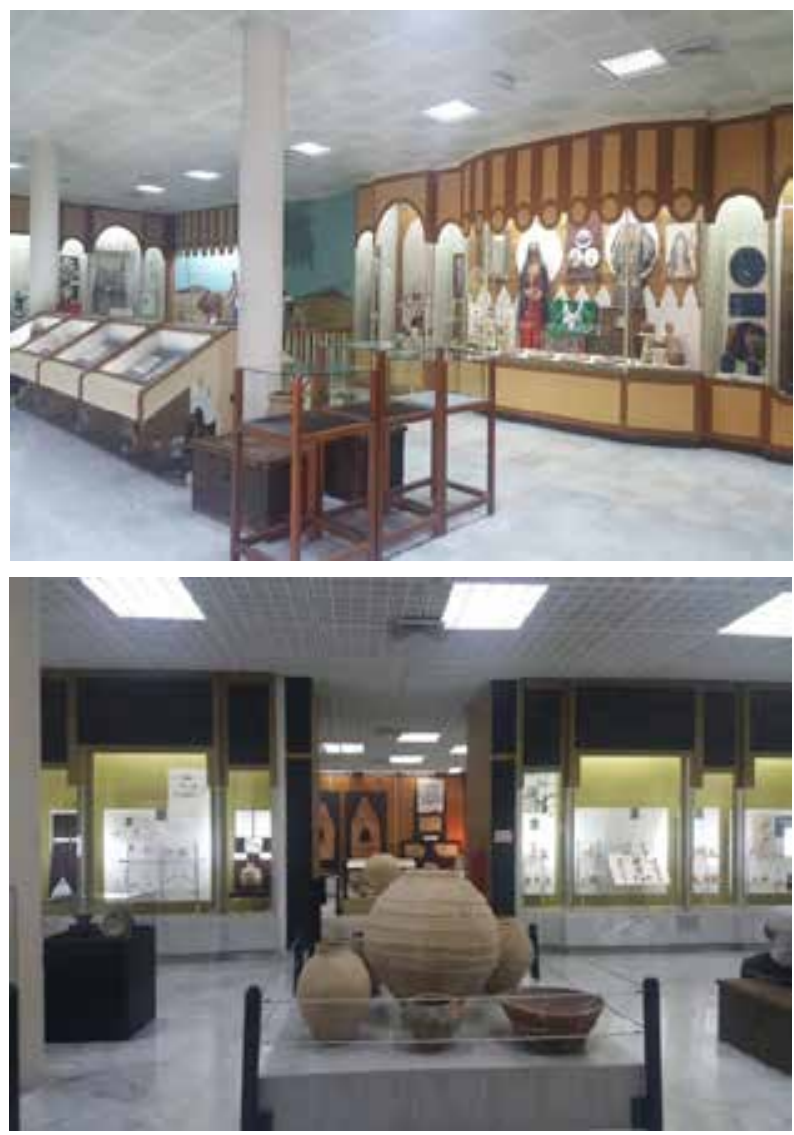

Fotoğraf 1 ve 2. Al Ain Ulusal Müzesi, 2018.

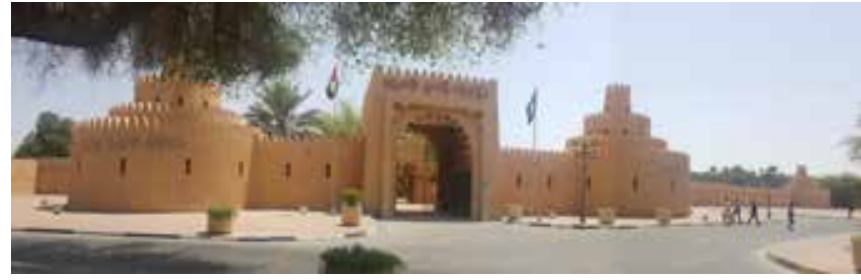

Fotoğraf 3. Al Ain Saray Müzesi, 2018.

Dubai'nin ilk müzesi 1971'de Dubai Kanalı olarak bilinen ticaret bölgesinde yer alan Al Fahidi Kalesi'nde bir ulusal tarih müzesi olarak kurulan Dubai Müzesi'dir. Statik sergilemenin ötesine geçmek amacıyla 1995'te müzeye modern bir galeri eklemiş, ilerleyen dönemde müze, Emirliklerin geleneksel çöl ve deniz yaşamıyla inci avcılığı, hurma tarımı gibi bölümlerin sergilendiği bir kültür merkezi halini almıştır. Müze 2000 yılına kadar sergilediği etnografik koleksiyonu koruyarak 2006'dan itibaren video, dijital ekran ve dokunmatik ekranlardan oluşan bir sergi tasarımı geliştirmiştir. Kanna (2011:22), müzenin çöl hayatıyla kanal yaşam biçimini bir araya getirerek yerel kültürel çeşitliliği vurguladığını belirtir. Bununla birlikte sergide aydınlık ve karanlık ortamların ve loş
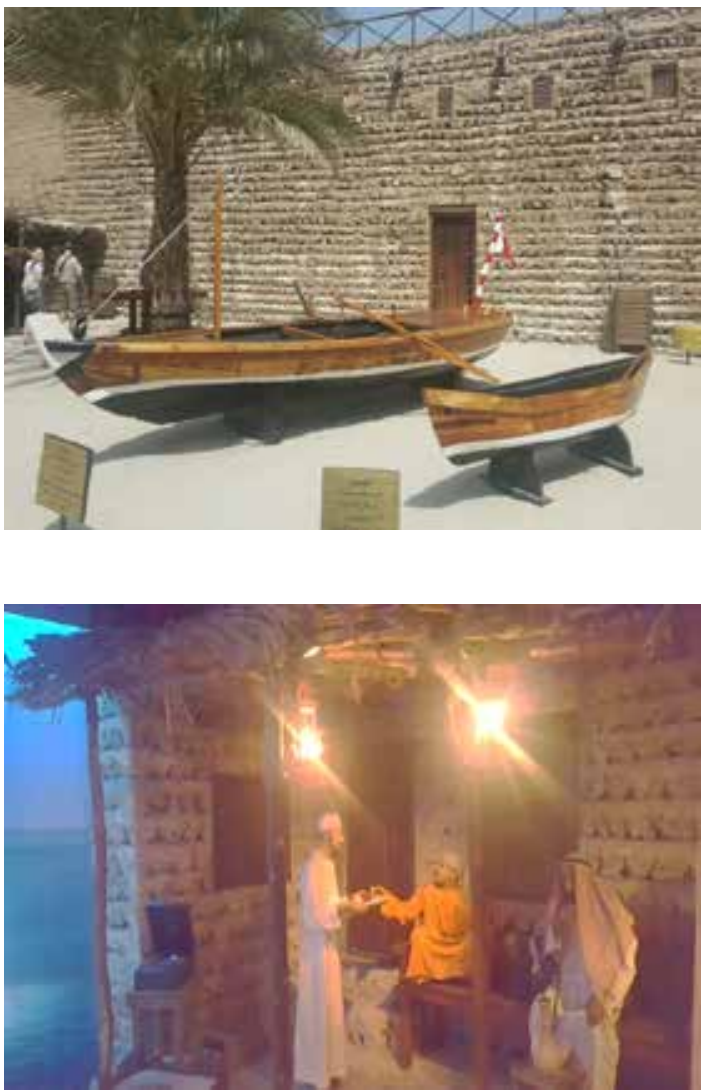

Fotoğraf 4 ve 5. Dubai Müzesi, 2018. 
ışıklandırmanın özellikle kullanıldığını, ışı oyunlarıyla bedevi çöl hayatı ile petrol sonrası modern yaşamın bir geçiş süreci gibi özellikle sunulduğunu (mitten moderne - çölden mega kente geçiş) ifade eder. Müze, sergi tasarımını çağdaş yaklaşımlarla ve teknolojiyle desteklemesine rağmen eğitim etkinliklerini rehberli müze turlarından öteye taşıyamamaktadır. Veldhuizen (2017:9), rehberli müze turlarını bilginin ziyaretçiyi edilgen kılınarak tek taraflı anlatımla ve etkileşim olanağından yoksun bir düzende aktarılması olarak tanımlamakta ve müzecilik tarihinin en eski ve yaygın eğitim etkinliği olduğunu vurgulamaktadır. Bu yöntem çok sayıda ziyaretçiye hizmet verilmesini sağlamakta ancak müzeyle istenilen düzeyde etkileşimi engellemektedir.

BAE'de ulusal kimliğin inşası sürecinde eğitim tarihi araştırmalarına hız verilerek Abu Dhabi, Dubai ve Sharjah'da eğitim tarihi ve okul müzeleri kurulmuştur. Bu bağlamda kurulan ilk okul müzesi Dubai'deki tarihi Al Ahmediya Okulunda kurulan müzedir (1994). BAE'nin yakın tarihini eğitim olgusu üzerinden yorumlamayı ve ülkenin modernleşme süresindeki eğitim yaklaşımlarını sunmayı amaçlayan müzede okulun derslikleri, öğretim programı materyali, öğrenme araçları ve öğrenim belgeleri - sertifikalar statik bir sergileme biçiminde balmumu heykeller kullanılarak sergilenmektedir. Burhaima (2011:36), 2003'de Sharjah'da kurulan Al Eslah Okul Müzesi'nin ulusal eğitimin geldiği düzeyi eğitim materyali üzerinden anlatmayı amaçladığını belirtirken bu müze türünün orijinal mimari bütünlüğüyle ulusal kültürü vurgulayacak biçimde geçmişin canlandırılmasını olanaklı hale getirdiği için tercih edildiğini ifade etmiştir. BAE'de müze birimi kurarak müzelerde uygulanacak çağdaş eğitim programları tasarlayan tek emirlik 1998 Arap dünyasının kültür başkenti olan Sharjah'dır. 1996'da İslam Uygarlıkları Müzesi'nin kurulmasıyla birlikte sistemli okul, yetişkin, aile ve toplum eğitim programları tasarlayarak hayata geçiren Sharjah Müze Birimi bünyesindeki bütün müzeleri uygulama laboratuarı olarak kullanmış ve nihayetinde 1999'da çocuk ve gençlere yönelik bir de keşif merkezi açmıştır. Uzun süre Arap Körfezi'ndeki en büyük ve kapsamlı müze olan İslam Uygarlıkları Müzesi 2005 'ten sonra geçirdiği restorasyon ve yenilenmeyle çağdaş müzeciliğin gerekliklerini yerine getirecek eğitim atölyesi, teknoloji kullanımına odaklanan sunumları ve uluslararası iş birlikleriyle gerçekleştirdiği geçici sergilerle öne çıkmış, 2009'da aile eğitimi programlarına katılımı \% 40, 2011'de ise \% 80 artırarak BAE'deki ilk sistemli ve sürdürülebilir müze eğitimi çalışmalarına imza atmıştır. Müzenin diğer müzelerden farkı 2011'de hazırladığı Öğretmenler için Müze Kaynak Kitapları'dır. BAE öğretim programlarıyla ilişkilendirilerek hazırlanan kitaplar tüm müze galerilerinde gerçekleştirilecek dersleri örneklendirmekte ve hala etkin biçimde kullanılmaktadır (Burhaima, 2011:38; Simonet ve Vincent, 2014:251).

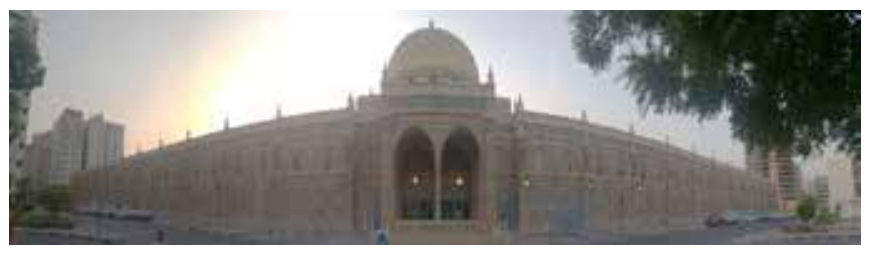

Fotoğraf 6. Sharjah İslam Uygarlıkları Müzesi, 2018

BAE'de Al Ain'dan sonra 2012'de yedi kültürel unsurun UNESCO Kültürel Miras Listesine girmesiyle birlikte ${ }^{3}$ ulusal kültürün vurgulandığı bir dizi yaşayan köy/tarih müzesi açılmıştır. Dubai Miras Köyü, Dubai Dalış Köyü ve Hatta Miras Köyü bu türün ülkedeki etkili ve etkileşimli örnekleridir. Prager'e (2015:38) göre bu kültür köyleri BAE'nin kültürel çeşitliliğinin açık biçimde izlenebildiği temsillerdir. Knell'e (2011:25) göre her emirliğin miras müzelerinde kendi kimliğini vurgulaması kimlik inşa etme politikasını destekliyor olsa da yeni kültür köyleri farklı kimlik ve toplulukları ortak kültüre dahil etme yaklaşımındadır. Öte yandan bu köylerde çalışan uzmanlar Pakistan, Afganistan, Bahreyn, Umman vb. ülkelerin vatandaşlarıdır, dolayısıyla yeni kültür köylerinin personel ve ziyaretçi çeşitliliğini göz önünde bulunduracak felsefe benimsemeleri ve uygulamaları zorunluluk halini almıştır. Khalaf (2002:23), yaşayan müze kavramını Körfez Bölgesi için ilk kez ele aldığında bu türün kültürün yaşatılması ve diğer kültürlerle etkileşime geçmesi için en uygun müze modeli olduğunu ileri sürmüştür. Yaşayan müze genellikle açık hava müzesi biçiminde planlanmış olup, tarihi ve kültürel ortamların canlandırılması ya da yeniden oluşturulması/ yorumlanması biçiminde karşımıza çıkmaktadır. Bu müzeler ziyaretçileri geçmişin kültürel gelenekleri ve uygulamalarını deneyimleyebilecekleri işitsel, görsel, tatma, dokunma ve koklamaya dayalı etkinlikler aracılığıyla kültürü yaparak ve yaşayarak kavrayabilecekleri etkileşimli ortamlar oluştururlar (Rojek, 1999:187; Magelssen, 2007:21). ABD ve Avrupa'daki örneklerin aksine BAE'deki miras köyleri konaklama, yemek pişirme, el sanatları vb. gündelik işlere daha sık yer vermektedir (Kirschblatt-Gimblett, 1998:45).

1997'de Al Shindagha tarihi bölgesinde kurulan Dubai 
Miras Köyü, Khalaf'a (2012:19) göre küresel yaşam biçiminin sosyal yaşamı büyük ve olumsuz ölçüde etkilediği BAE'de zamana ve değişime direnç niteliğinde kurulmuş, ulusal kimliği inşa etmeye ve sürdürmeye adanmış bir kurumdur. Müzede tematik sergileme benimsenmiş, Ras al Khaimah'da yaşayan dağ kabileleriyle bedevilerin yaşam biçimleri 20 atölye, dört sergi alanı, açık hava tiyatrosu, geleneksel pazar (Souq) ve folklor gösteri alanından oluşan geniş bir alanda ziyaretçiyle buluşmuştur. Miras Köyü aynı zamanda Bennet'in (1988:74) söz ettiği sergi, fuar ve satışı bir arada bulunduran bir "sergi kompleksi” örneğidir. Dubai'nin kadim geleneklerinden biri olan inci avcılığı da müzenin ana temalarından birini oluşturmaktadır. Yerinde sergileme yaklaşımının ileri düzeyi olarak kabul edilen Dubai Miras Köyü'nde geleneksel sanatları icra eden kadınlar ve inci avcısı erkekler kültürel miras aktörleri olarak etkinliklerde görev alarak ziyaretçileri bilgilendirir ve geleneklerini devam ettirirler. 1997'de Dalış Köyü ise bünyesindeki ulusal dalış merkeziyle geleneksel inci dalışı ve avcııı̆ıyla ilgili deneyimleri sürdürmektedir. 2003'de inci avcılığı ve ticaretine ilişkin mirası korumak ve yaşatmak amacıyla Dubai'de bir de İnci Müzesi kurulmuştur. Hajaran Dağı'nda 2001'de kurulan Hatta Miras Köyü'nde ise 30 bina, tatlı su kanalları (falaj) ve arkeolojik bir mezarlık bulunmaktadır. Köy orijinal prototipler, modeller, belgeler, maketler/ heykeller, illüstrasyonlar ve çeşitli grafik/ ses materyali içerdiği için Dubai Emirliği'nde geleneksel dağlık kırsal yaşam modelini 17 yerel ev ve iki kale arasında keşfetmek fırsatı sunmakta ve geleneksel köy yaşantısı bağlamında yerel folkloru devam ettirerek kültürün aktarımına olanak sağlamaktadır (Hurreiz, 2002:33). Köy BAE Ulusal Günü, Dubai Alışveriş Festivali ve Bayrak Günü etkinliklerine ev sahipliği yaparak yerel kalkınmaya destek vermektedir.

2000'den sonra Dubai'de iş adamlarının ve sanatçıların kişisel koleksiyonlarını müze haline getirdikleri görülür. Saruq Al-Hadid Arkeoloji Müzesi, Naif Kalesi Müzesi ve Şair Al Oqaili Müzesi, Para Müzesi, İnci Müzesi, Salsali Sanat Müzesi, Kahve Müzesi, Sinema Tarihi ve Hareketli İmajlar Müzesi ve Kadın Müzesi gibi örnekler aynı zamanda BAE'nin ilk özel müzeleri olarak da öne çıkar. Bu müzeler içinde 2012'de Dubai'de kurulan kadın müzesi koleksiyonu, söylemi ve etkinlikleriyle diğerlerinden ayrılır. Müze 1980'e kadar dinin ve siyasetin toplum yaşantısına katılımını sınırlandığı kadınların 2000'lerin başından itibaren devlet kurumlarında ve özel sektörde hızla artan istihdamını tarihi belgelerle anlatırken (Farrel,
2008:109; Nelson, 2004:32); geleneksel Emirlik yaşam biçiminin kadının hayatını geçmişte ve günümüzde nasıl şekillendirdiğini de irdelemektedir. Müze aynı zamanda Dubai'nin kadın çalışmaları konusunda araştırmalar yapan ilk bilimsel araştırma merkezini de içermektedir, böylece BAE'de işlevlerinden biri de araştırma olan tek müze olarak dikkat çeker.

Dubai'den sonra Abu Dhabi de özel müze ve sanat kurumlarının açılışı sürecini 2015'te Warehouse 421 ile başlatmıştır. Bir çağdaş sanat müzesi olan Warehouse, aynı zamanda geleneklere odaklanan sürekli sergileriyle dikkat çeker. Galeri, Abu Dhabi'de üniversitelerin sanat bölümlerinde eğitim gören öğrenciler, yerel ve uluslararası sanatçılar, galeri sahipleri ve koleksiyonerleri bir araya getiren bir buluşma noktasıdır. Artun (2015:13) şeyhlerin Abu Dhabi'yi ülkenin sanat merkezi ve Dubai'yi ise paranın ve turizmin merkezi yapmaya kararlı olduklarını vurgular. Bu bağlamda ulusal kimliği ve yerel kültürü destekleyen müzeler dalgası Dubai'de irili ufaklı özel müzeler açıldıktan sonra yavaşlamış, yerini popüler ve evrensel müzeler dalgasına bırakmıştır. Louvre ile Guggenheim Müzelerinin Abu Dhabi'de birer şube açma girişimleri emirliği BAE'nin sanat başkenti haline getirme çabaları olarak yorumlanmaktadır (Davidson, 2014:212). Artun (2015:16), BAE'de sanatsal yapılanmanın merkezi olan Abu Dhabi'nin şimdiden çağdaş sanat koleksiyonlarına 520 milyon dolar ayırdığını belirtmektedir.

\section{Louvre Abu Dhabi ve Ötesi}

Sylvester’a (2009:2) göre Louvre Abu Dhabi uluslararası ilişkilerin çağdaş bir vitrini ve sanat - müze birlikteliğinin önemli bir örneğidir. BAE'nin en pahalı kültür yatırımı olarak BAE ve Fransa hükümetleri arasında imzalanan anlaşmayla 2007'de temelleri atılan Louvre Abu Dhabi, aynı Abu Dhabi emirliği gibi “dünyaya açık bir ruha sahip”, hem temsil ettiği kültürler hem de ziyaretçi çeşitliliği bağlamında misafirperver bir yaklaşımla kültürlerarası diyaloğu geliştirmeyi hedefleyen bir müze olarak tanıtılmıştır (Mubarak ve Martinez, 2017:4). 2012'de yapılması beklenen resmi açılış petrol fiyatlarındaki düşüşle birlikte yaşanan ekonomik kriz nedeniyle 2017'ye ertelenmiştir. Müze 2017'de açıldığında müzenin Paris'teki Louvre Müzesi'nin Arap Körfezi'ndeki bir şubesi olmanın ötesinde bölgede kendi kimliğini ve dinamiğini oluşturarak ve uluslararası bir müze olarak zaman ve mekân ile sınırlandırılamayacak evrensel bir misyonu temsil etmek amacında olacağı vurgulanmıştır. Fransa Cumhurbaşkanı Emmanuel Macron mü- 
zenin açılışındaki konuşmasında Louvre Abu Dhabi’nin Arap ya da Fransız kültüründen bir alıntıyla değil ancak dünyaca ünlü yazar Dostoyevski’nin bir cümlesiyle doğru ifade edilebileceğini vurgulamıştır: “dünyayı güzellik kurtaracak”(Macron, 2017). Macron tarafından insanlığın eğitim ve sanat alanında ulaştığı en yüksek seviye olarak tanımlanan müzeye 2019'un sonuna kadar Guggenheim, Zayed Ulusal Müzesi, Performans Sanatları Müzesi ve Denizcilik Tarihi Müzesi eşlik edecektir.

Fransız Müzeler Ajansı'nın danışmanlığında oluşturulan müzenin kuruluşu sırasında Müze d’Orsay, Pampidou Sanat Merkezi, Fransa Ulusal Kütüphanesi, Ulusal Asya Sanatları Müzesi, Versaille Müzesi ve Rodin Müzesi gibi kültür merkezlerinden 300 nesne ödünç alınmış; 600 nesne ise satın alma yoluyla, bağışla ve doğrudan Louvre Paris koleksiyonundan derlenerek müzeye kazandırılmıştır. 55 galeri ve 23 sabit sergi alanından oluşan müze mimar Jean Nouvel'in tasarımıdır ve BAE'nin coğrafi özelliklerinden de esinlenerek çöl güneşini içeri alacak şekilde tasarlanmıştır. Nouvel bu kubbe ile Abu Dhabi'nin artık farklı bir ışık altında parlayacağına vurgu yaparak müzeyi ziyaretin izleyicinin ruhunu yenileyeceğini, dehanın gücüne şahitlik etme şansı vereceğini ve geçmişin mucizelerini yeniden keşfetmeye olanak sağlayacağını da eklemiştir. Macron (2017) da Nouvel'i destekleyerek açılış töreninde müzeyi ışık oyunlarına ev sahipliği yapan bir şehir olarak tanımlamış, müze galerilerini Emirliklerdeki köy evlerine benzetmiş, insanda derin duygular uyandıran üst düzey bir mimari başyapıtla karşı karşıya olunduğunu belirterek müzenin bir "güzellik tapınağı” olduğunu sözlerine eklemiş, BAE'nin Louvre Abu Dhabi’yle birlikte doğu ve batı kültürlerini buluşturan ve yüzünü Avrupa'ya, Arap Dünyasına, Hindistan ve Çin'e çeviren bir küresel merkez olma özelliğine kavuştuğunu vurgulamıştır. Macron'a (2017) göre Louvre Abu Dhabi Malraux'un sözünü ettiği “hayali müze”dir ${ }^{4}$. Böylece Louvre’a giren eser entelektüel bir değer kazanmış, temsiliyetlerini ve manevi değerlerini yeniden ele almışlardır.

Prehistorik döneme tarihlendirilen nesnelerden çağdaş sanatın önemli temsilcilerinin yapıtlarına kadar farklı dönemlerden eserlere ev sahipliği yapan müze, sıra dışı mimarisini ana avluda bir açık hava galerisi oluşturulmuş; galeriye Giuseppe Penone'un "Hayat Ağacı" ve Jenny Holzer’in "Sümer Yaratılış Miti” isimli sanat çalışmaları yerleştirilmiştir. Holzer, Sümer Yaratılış Mitini çivi yazısıyla yazmış, yanına Michel de Montaigne'in kendi ben'inde insanı bulmaya yönelik düşünceleri ile İbn Haldun'un Mukaddime eserinde yer alan "beşer” kavramlarını yerleştirerek Louvre'un üzerinde bulunduğu $B A E$ gibi önemli bir kültürlerarası etkileşim merkezi olduğunu vurgulamaya çalışmıştır.

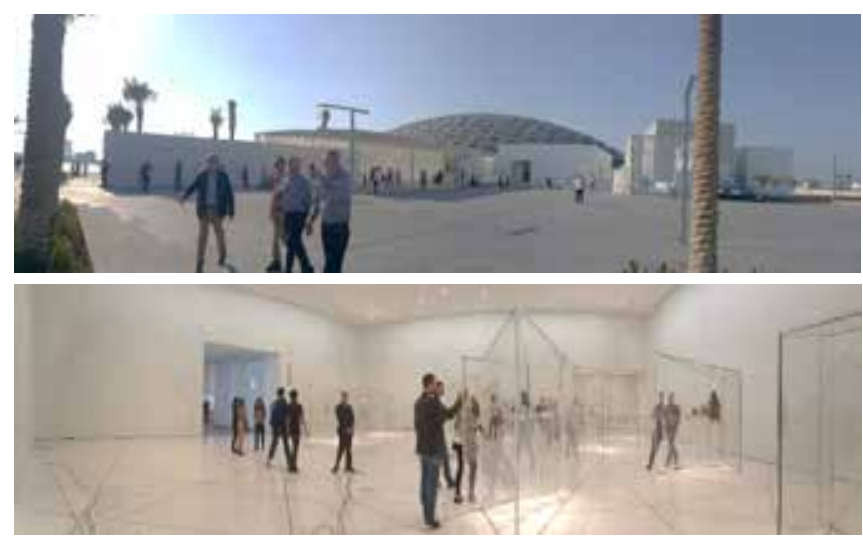

Fotoğraf 7 ve 8. Louvre Abu Dhabi, 2018

Uygarlıkların kesişme noktasında çağdaş müzecilik yaklaşımlarını hayata geçirme vizyonuyla açılan müze başta mimari ve sergi tasarımı olmak üzere eğitim ve tanıtım etkinliklerinde de birçok yeniliği ve çelişkiyi de gündeme getirmiştir. Örneğin, Cotter'e (2017) göre Louvre Abu Dhabi'deki Batı uygarlıklarına ilişkin nesnelerle diğer uygarlıkların örneklerinin yan yana sergilenmesini sergi tasarımı bağlamında yenilikçi ve cesur bir girişim olarak değerlendirilmektedir. Müzede sergi tasarımı kapsamında tematik bir yaklaşım geliştirilmiş, eserler sosyolojik bağlamlarıyla değerlendirilerek yorumlanmıştır. Örneğin bebeğini besleyen Mısır tanrısı İsis'in bronz heykeliyle 14. Yüzyıla tarihlenen fildişi Hz. Meryem ve bebek İsa heykelciği ve 19. yüzyılda Demokratik Kongo Cumhuriyeti'nde yapılmış ahşap anne ve çocuk heykeli bir arada sergilenerek anneliğin kültürlerarası benzerliğini vurgulamaktadır. Peru, Suriye ve Çin'de farklı dönemlerde değerli madenlerden ve taşlardan üretilmiş törensel maskelerin yan yana sergilenmesi ölümsüzlük ya da hatırlanma kavramlarının farklı kültürlerdeki benzerliklerini anlatmayı amaçlamaktadır. Bu karma sergileme yaklaşımı ziyaretçi katılımını artırabileceği gibi eğitim amacıyla kullanımı da kolaylaştıracaktır. Louvre Abu Dhabi bu sergileme biçimiyle çeşitli kültürlerarasındaki bağlantılara dikkat çekerek sanatın hedeflediği üzere küresel bir izleyici kitlesini müzeye çekebileceği iddiasına dayanmaktadır. İzleyiciler bu bağlantıyı saptadıklarında tüm kültürlerin eşit derecede değerli ve birbirleriyle bağlantılı olduklarını anlayacaklardır. Bu yaklaşıma karşı görüşler de sunulmuştur. Müze, koleksiyonunu 2014’te Louvre'da açılan “Bir Müzenin 
Doğuşu” sergisiyle tanıtmış, bu tanıtımda koleksiyonun bir bütünlük sağlamadığı ve bir fikri olmadığı gerekçesiyle eleştirilmiştir.

Louvre için farklı bir eleştiri nedeni de koloniciliğin müzede sergilenme biçimidir. Bir “Arap Dünyası” müzesinde Müslüman Kuzey Afrika’nın sömürgeci ve işgalci Napolyon'un imgelerine yer vermesi de ayrı bir tartışmayı doğurabilecektir. “Modern Oryantalizm” başlığı altında toplanan galeride sergilenen 19. ve 20. yüzyılın başlarına tarihlenen çalışmaların bir kısmı sömürgeciliğin sanat üzerindeki etkisini gözler önüne sermektedir. Çağlar boyunca ve özellikle Arap Yarımadası'nda birçok bölgede yaygın olan köleliğe hiçbir şekilde müze içinde yer verilmemesi de ayrıca dikkat çekmektedir. Müzede "Savaş Sanatı" isimli bir galerinin yer alması savaşın bir müze tarafından sanat olarak algılanmasının çarpıcı bir örneğidir ve ataerkil kültürün açık bir sunumu niteliğindedir. Bu nedenle Cotter'e (2017) göre Louvre Abu Dhabi çoğu zaman nesnelerin gerçek bağlamlarını yansıtmak konusunda yetersiz kalmaktadır. Bu yetersizlik geçmişi yansıtma biçiminin yanı sıra bugüne yansıttıklarındaki çelişkide de izlenmektedir. Müze vizyon ve misyonunu açılmadan aylar önce çeşitli reklamlarla tanıtmış, "herkesin müzesi” olacağını, "insanlığa yeni bir ışık yakacağını”, “açıklık ve uyum merkezi olarak çalışacağını” ve "anlayışlı ve kabul edici bir çevre tasarlayacağını" iddia etmiştir. Oysa müze, inşaatına başlanan 2007'den beri göçmen işçilerin olumsuz çalışma koşulları nedeniyle insan hakları örgütleri, sanatçılar ve aktivistler tarafından sıkça protesto edilmiştir. Bununla birlikte müzenin açılış haftasında İsveçli iki gazeteci inşaat işçileri hakkında kısa bir haber yapmışlar ve bu sebeple tutuklanarak sınır dışı edilmişlerdir. Müze inşaatına başlandığından beri onlarca sanatçı, aktivist ve gazeteci müzeyi protesto ettikleri için sınır dışı edilmiş, ülkeye girişleri engellenmiştir. Müzenin “herkesin müzesi olma” yönünde sergilediği bu tavır dikkat çekmiştir.

Cotter'e (2017) göre sergileme ve yaklaşımın yanı sıra "sıradışı" mimarisinde de çeşitli sıkıntılar vardır. Nouvel'in başyapıtı bölgesel dinamikleri temsil etmeye çalışırken bir uzay aracına, yarım kalmış bir camiye ya da İran Körfezi'nde inşa edilmiş bir Venedik Köşküne benzediği için eleştirilmektedir. Cotter (2017), Louvre Abu Dhabi’nin bir fabrikasyon bina olduğunu ve 1,15 milyar dolar karşılığında geçici süreliğine kiralanan bir marka olduğunu ve mimari çekiciliğiyle bu geliri katlamayı hedeflediğini de hatırlatmaktadır. Küçük (2017) de mimari gelişmelere ilişkin eleştirilerden yola çıkarak Louvre ile hayat bulmaya başlayan Saadiyat Adası'nın çölde bir sanat vahası mı yoksa distopik bir müzeler adası mı olacağını zamanın göstereceğini belirtmiştir, çünkü bu distopik adanın geleneksel ve yerel kodlarla hiçbir ortak noktası yoktur. Öte yandan Saadiyat Adası Batı'da hızla gerileyen İslami ideolojinin olumsuz izlenimlerini besleyen olaylara karşı gelebilmek amacıyla yerel ya da turistik bir kimlik oluşturma projesidir (Ajana, 2015:326). McClellan (2012:281) bu yatırımın BAE'de huzurlu ve güvenli bir İslam'ın savunulduğunun ve uygulandığının göstergesi olarak yapıldığını ifade eder. Bununla birlikte Shadid'in (2012) mega müze projelerine rağmen yerel halkın kültürel kimliğin kaybına ilişkin çekinceleri olduğunu vurgulaması ve ülkede kültürel mirasın yalnızca "turizmi kalkındırmak” söz konusu olduğunda hatırlandığına ilişkin eleştirilerin artması dikkate değer gelişmelerdir. Dolayısıyla ulusararası platformda boy gösteren markalaşmış BAE müzelerinin bu eleştirileri nasıl ortadan kaldıracakları ve kültürel kimliğin ve çeşitliliğin korunarak sürdürülmesi bağlamında nasıl bir felsefeyle izleyiciyle buluşacakları merak konusudur.

Tadao Ando, Norman Foster, Frank Gehry, Zaha Hadid, Jean Nouvel, Icoh Ming Pei ve Jean Michel Willmotte gibi dünyaca ünlü mimarların önemli büyük bütçeli müze projelerinin birbiri ardına Arap Yarımadasında açılıyor olması bize ne anlatıyor? Bu müzelerin bulundukları ülkelerin kültürel yapılarına uygunluğu tartışma konusuyken British Museum, Guggenheim ya da Louvre gibi dünyaca ünlü müzelerle rekabet etmeleri için zamandan ve ülkeden bağımsız olarak modernizmi bulundukları topraklara taşımak üzere kuruldukları iddia edilmekte, bölgelerinde yerel kimliklerin inşa edilmesine ön ayak oldukları, ulusal ve uluslararası müze izleyicilerinin kültürel ihtiyaçlarını giderdikleri, bölgenin modernizmi anlamasına ve kabul etmesine yardımcı oldukları ve küresel kültür dünyasına katkı sağladıkları da öne sürülmektedir (Exell ve Rico, 2014:8). Karp vd. (2006:12-13) ise çağımızda küresel miras yönetiminde ve müzecilikte uluslararası bağlantıların kurulduğu ve küresel oryantasyonların uygulandığı iş birliğine dayalı bir dönem yaşandığını, dolayısıyla bu gelişmelerin farklı ülkelerde benzer özellikler taşıyan “evrensel” müzeleri doğurduğunu vurgulamaktadır. Vivant (2011:101) da bu evrensel müzelerin aynı zamanda müze markalarının küreselleşmesine ve 'girişimci müzeciliğin yaygınlaşmasına' katkı sağladığını belirtir. Ancak yeni Körfez müzelerini şiddetle eleştiren sanat eleştirmenleri de vardır. Ouroussoff (2010) bu müzelerin ev sahipliği yaptığı koleksiyonların sınıflandırmasının, bakım 
onarımlarının, sosyolojik bağlamlarının, sergi tasarımlarının ve hatta eğitim programlarının hep Batılı uzmanlarca yapıldığını vurgulayarak yerel müzecilerin yetiştirilmesi konusunda özen gösterilmediğine dikkat çekmektedir.
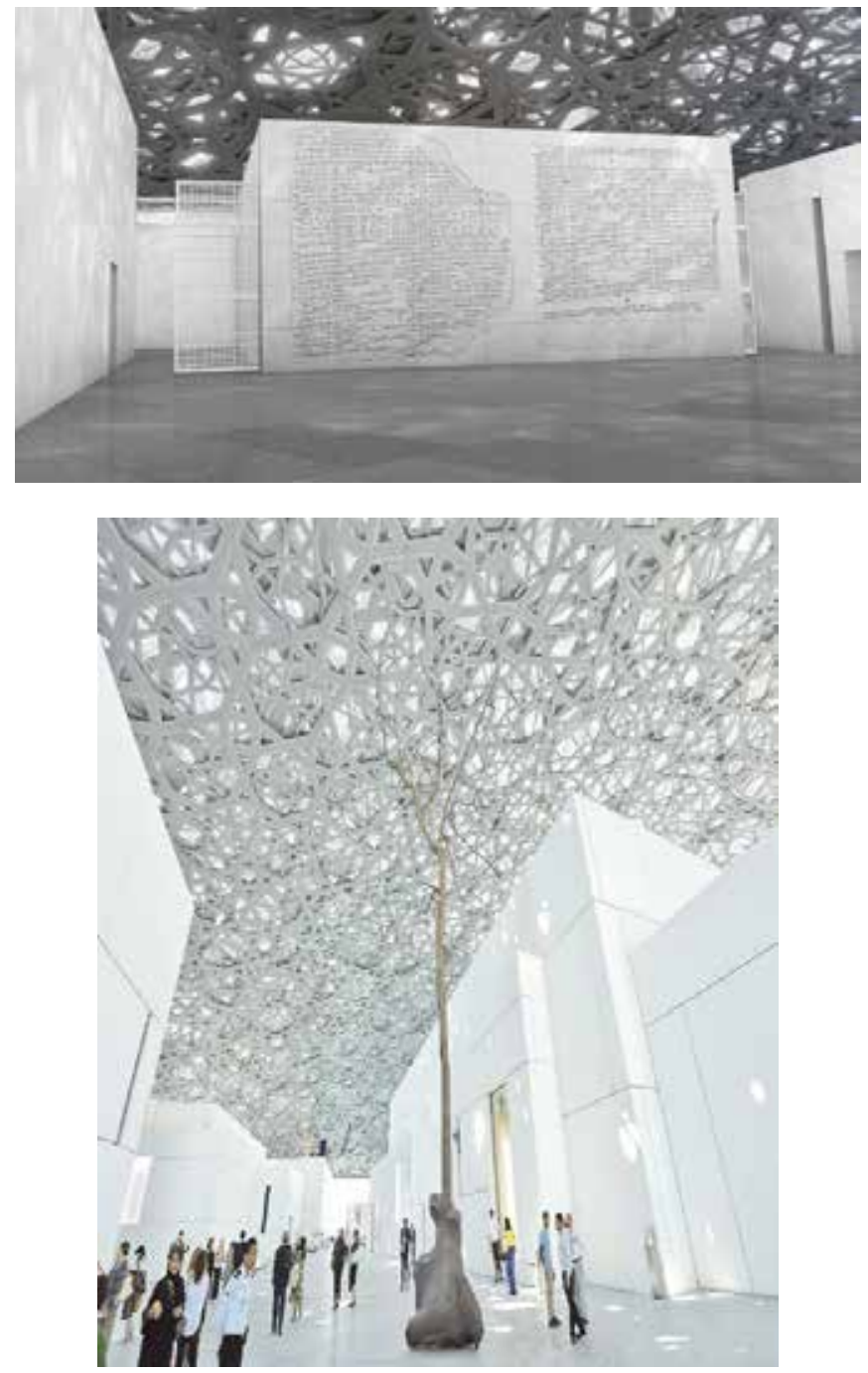

Fotoğraf 9 ve 10. Jenny Holzer, Sümer Yaratılış Miti ve Giuseppe Penone "Hayat Ağacı", 2018.

\section{Sonuç}

BAE'de 1970'den sonra petrole dayalı endüstrinin kalkınmayı biçimlendirmesiyle birlikte aidiyet, ulus ve kimlik inşası süreci gündeme gelmiştir (Exell ve Rico, 2013:671). Aynı yıldan itibaren ülke genelinde arkeolojik kazıların başlatılması, müze vb. kültür ve miras kurumlarının açılmasının sebebi de aynı gelişmelerdir. Bu gelişmelerden hareketle BAE'nin somut ve somut olayan ulusal kültürünü yansıtacak ve aynı zamanda evrensel kültürle bütünleşecek müzeler kurmak, çeşitlilik içeren izleyici kitlelerini kültür kurumlarına çekebilmek, yerel halkın kültür, bilim ve sanata ilgisini artırmak, kültür, bilim ve sanat alanında etkileşimli deneyimler sunacak çağdaş merkezler oluşturmak ve halkın kültür, bilim ve sanat alanlarında kariyer planlamalarını sağlamak kültür politikasının temellerini oluşturmuştur. Bu süreçte açılan müzelerin çoğu sergi tasarımında geleneksel ve statik yaklaşımları benimsemiş ve ziyaretçiyi sürece dahil edecek çağdaş bir sunumu henüz hayata geçirememiştir. Geleneksel sergilerde ziyaretçinin müzeye ve sunuma yabancılaşması en sık karşılaşılan ziyaretçi davranışıdır (Roppola, 2012:58). BAE'de ziyaretçinin sürece dahil edildiği az sayıda uygulamaya ise daha etkileşimli olanaklar sunan miras köylerinde rastlanmaktadır. BAE'deki müzelerin genellikle otoriteyi temsil edip ulus inşası politikasını desteklerken ülkedeki etnik grupları ve göçmenleri senaryo ve sunum dışı bıraktıkları da dikkat çeker.

Al Ain Ulusal Müzesi'nin 1969'da açımasıyla başlayan ulusal kimlik oluşturma süreci 2017 sonunda 100'e ulaşan müze sayısıyla ulusötesi boyutlara taşınmış, Arap Körfezi'nin en güçlü ekonomilerinden biri olan BAE'yi bulunduğu coğrafyanın kültür merkezi haline de getirmiştir. Ekonomiyi çeşitlendirme politikaları doğrultusunda 2030 hedefi miras endüstrisini cazip ve popüler hale getirmek ve bu süreçte kültürel miras ve turizm bağlamında toplumsal gelişmeyi desteklemektir. Kültür ve miras çalışmalarının dayandığı temel amacın turizm gelirlerini artırma çabası olduğu ülkede Louve'un açılması ülke ekonomisini petrol gelirlerinden öteye kültür ve sanat ağırlıklı turizme taşıma ve görünür kılma çabalarının önemli bir örneğidir (McClellan, 2012:275). Aynı zamanda Abu Dhabi ve Dubai arasında devam eden turizm, sanat ve kültür merkezi olma mücadelesini Abu Dhabi lehine çevirmiştir. Öte yandan Abu Dhabi'nin bu süreçte eli kuvvetlense de Dubai'nin fütüristik tasarımlara yer verecek “Geleceğin Müzesi” projesini hızla sonlandırma çabası da dikkat çekmektedir. BAE son on yılda yaşanan müze patlamasını nitelikli insan gücüyle karşılayabilmek, kültürel mirası profesyonelce yönetmek ve miras eğitimini yaygınlaştırmak amacıyla New York Üniversitesi ve Sorbonne Üniversitesi gibi okulları ülkeye davet etmiş, bu okullarda müzecilik, kültürel miras çalışmaları ve çağdaş sanat alanlarında lisans ve lisansüstü programlar açmıştır. Bu programlarda müze koleksiyonlarının sınıflandırılması, bakım onarım faaliyetlerinin gerçekleştirilmesi, çağdaş sergi tasarımlarının oluşturulması, müze eğitiminin planlanması gibi müzebilim dersleriyle, müze izleyicisi geliştirme, 
müze projeleri hazırlama, planlama ve yönetim, çağdaş sanat ve sanat yönetimi, müzeler ve medya çalışmaları gibi dersler okutulmaktadır.

Emirileştirme politikası uygulanırken öncelikle kendi kimliklerini BAE ulusal kimliğiyle bütünleştirerek tanıma ve tanıtma amacıyla çalışan müzeler, zamanla ulusal kültür tanıtımının ötesine geçerek Arap Körfezi'ndeki turistik yatırımlarının artması, yeni çekim ve cazibe şehirlerinin oluşturulması gibi nedenlerle ülke turizmininin gelişimini doğrudan etkileyen kurumlar haline gelmişlerdir. Bu çarpıcı müzeler ulus ötesi ortaklıklar ve neoliberal kültür politikalarının sonucu olarak ortaya çıkmıştır. Louvre Abu Dhabi'nin açılması eleştirilerle birlikte BAE'nin kültürel mirasını Emirileştirme ülküsüyle sadece kendi insanlarıla değil, ülkesine gelen turistlerle de paylaşma çabasını göstermiştir. Arap Körfezi'ndeki Umman, Bahreyn, Kuveyt ve Suudi Arabistan gibi ülkelerin uluslararası turizm pazarından pay alma çabalarının zamanla BAE ile rekabet edebilir hale gelmelerini sağlamış ve BAE'nin kültürel mirasın korunması, geliştirilmesi, sürdürülmesi ve eğitimine odaklanan yeni bir kültür politikası geliştirmesine katkı sağlamıştır. Bu politikanın uygulanması sadece müzeleri değil ülkedeki tüm kültür kurumlarını araç olarak kullanmayı ve BAE nüfusunun göçmen bakımından zengin, farklı ve hiyerarşik doğasını göz önünde bulundurmayı gerektirmektedir. Abu Dabi ve komşu Körfez ülkeleri, dünyanın en hızlı gelişen bölgelerinden birinde dinamik ve yeni bir paradigmayı vaat ediyorlar. Bu durum BAE'yi Arap Körfezi'nde UNESCO kültürel miras listesindeki çarpıcı kültür varlıkları, yeni gelişen müzeleri ve çağdaş otelleriyle Umman ve ekonomiyi ve toplumsal hayatı dönüştürmeyi hedefleyen "yaşam tarzı hamlesini” müzeler başta olmak üzere çok sayıda kültür kurumu açarak hayata geçiren Suudi Arabistan gibi rakiplerle karşı karşıya getirmekte ve kültürel miras ve müzecilik rekabetinde BAE'nin yakın zamanda yeni kültür kurumlarıyla ve tartışmalarla gündeme geleceğini göstermektedir.

\section{Notlar}

1- Sadece Dubai Emirliği’ne ilişkin veriler paylaşılmıştır.

2- World Travel and Tourism Council Travel \& Tourism Economic Impact 2017 United Arab Emirates 2017, https:// www.wttc.org/-/media/files/reports/economic-impact-research/countries-2017/unitedarabemirates2017.pdf

3- Umm an-Nar Adası yerleşim yeri (2012), Sir Bu Nair Adası (2012), Khor Dubai (2012), Ed Nur Arkeolojik Alanı (2012), Sharjah Emirliği Kültür Bölgesi (2012), Al Bidya Cami (2012) ve Sharjah Emirliği Ticaret Alanı (2014).
4- Hayali Müze (La Musée Imanginaire), yazar ve düşünür André Malraux’nun 1935-1947 yılları arasında müzecilik ve sanat tarihi üzerine yazdığı aynı adlı kitapta sözünü ettiği müzedir. Eserler müzeye girmeden önceki özgün ortamlarındaki temsiliyetlerini, manevi değerlerini yitirmişlerdir. Müzelere girdikten sonra ise entelektüel bir önem kazanırlar.

\section{Kaynaklar}

Ajana, B. (2015). Branding, legitimation and the power of museums: The case of the Louvre Abu Dhabi. Museum \& Society. 13 (3): 316-335.

Akbay, O. S. (2013). Türkiye’nin Ortadoğu İle Ekonomik İlişkileri, Akademik Sosyal Araştırmalar Dergisi, Yıl: 1, Sayı: 1, 87-101.

Al Ain Palace Museum Activity Guide (2017). Introduction to Cultural Guide. Abu Dhabi: Abu Dhabi Tourism \& Culture Authority.

Al Ali, S. R. M. (2015). Rethinking Visitors Studies for the United Arab Emirates: Sharjah Museums as Case Study. Thesis of Doctor of Philosophy. School of Museum Studies University of Leicester, UK.

Al Jahili Fort Activity Guide (2017). Abu Dhabi: Abu Dhabi Tourism $\&$ Culture Authority.

Al Nayadi, A., M. (2013). The Al Ain National Museum. Museum International, 63 (3-4), 25-34.

Artun, A. (2015). Çağdaş Sanatın Örgütlenmesi. İstanbul: İletişim Yayınları.

Ataman, M.; Demir, N. G. (2012). Körfez Ülkelerinin Ortadoğu Politikası ve Arap Baharına Bakışları, SETA Analiz| Siyaset, Ekonomi ve Toplum Araştırmaları Vakfı, Sayı: 52, 4-5.

Bennet, T. (1988). Exhibitionary complex, New Formations, 4: 73 102.

Bouchenaki, M. (2013). The Extraordinary Development of Museums in the Gulf States. Museum International, 63(3-4): 93-103.

Bouchenaki, M.; Kreps, C. (2016). Making sense of the Arabian Peninsula museums. In Museums in Arabia: Transnational Practices and National Processes, pp. 15-22, (ed. Karen Excell \& Sarina Wakefield. UK: Routledge.

Bouquet, M. (2012). Museums: A visual anthropology. UK: Berg Publishing.

Burhaima, A. (2011). Programmes Designed for Visitors to the Museums of Sharjah. Museum International, 63 (3-4): 3540.

Cotter, H. (2017). Louvre Abu Dhabi, an Arabic-Galactic Wonder, Revises Art History.

Davidson, M.C. (2009). Abu Dhabi: Oil and Beyond. US: Columbia University Press.

Exell, K., \& Rico, T. (2013). 'There is no heritage in Qatar': Orientalism, colonialism and other problematic histories. World Archaeology 45(4), 670-685. 
Exell, K.; Rico, T. (eds). (2014). Cultural Heritage in the Arabian Peninsula: Debates, Discourses and Practices. UK: Ashgate.

Farrell, F. (2008). Voices on Emiratization: the impact of Emirati culture on the workforce participation of national women in the UAE private banking sector, Journal of Islamic Law and Culture, 2 (2), 107-168.

Ghobash, M. (2012). My Identity. Dubai: Shamsa Bint Suhail Publication.

Hacıoğlu, N.; Saylan, U. (2014). Arap Baharı'nın Turizme Yansımaları: Arap Ülkeleri ve Türkiye. Balıkesir University The Journal of Social Sciences Institute, 17 (32), 55-80. https://www.nytimes.com/2017/11/28/arts/design/ louvre-abu-dhabi-united-arab-emirates-review.html adresinden 04.06.2017 tarihinde erişilmiştir.

Hurreiz, H. S. (2002). Folklore and Folk Life in the United Arab Emirates. London: Routledge.

Jasim, A. A. (2008). Emiratisation: drawing UAE nationals into their surging economy, International Journal of Sociology and Social Policy, Vol. 28 Issue: 9/10, pp.365-379.

Kanna, A. (2011). Dubai: The city ay cooperation. Minneapolis: University of Minnesota.

Karp, K.; Kratz, C. A.; Szwaja, L. And Ybarra-Frausto, T. (eds). (2006). Museums Frictions: Public Cultures, Global Transformations. US: Duke University Press.

Khalaf, S. (2002). Globalization and heritage revival in the Gulf: An anthropological look at Dubai Heritage Village. Journal of Social Affairs 18 (75), 13-42.

Khalaf, S. (2012). Globalization and heritage revival in the gulf: an anthropological look at Dubai Heritage Village. Journal of Social Affairs, 19 (75), 13-42.

Kirschblatt-Gimblett, B. (1998). Destination culture: Tourism, museums, and heritage. USA: University of California Press.

Knell, S. (2011). National museums and national imagination. In S.J. Knell at all (Eds.). National museums - New Studies from around the World (pp.3-28). UK: Routledge.

Kocalar, 0. A. (2016). Ortadoğu Coğrafyasında Turizm. Yeni Türkiye, 82:117-125.

Küçük, C. (2017). Louvre Abu Dhabi Açıldı: Körfez’in Evrensel Müze Teşebbüsü. E-Skop Bülten. http://www.e-skop.com/ skopbulten/louvre-abu-dhabi-acildi-korfezin-evrenselmuze-tesebbusu/3581\#_edn5 adresinden 15.11.2017 tarihinde erişilmiştir.

Lorch, D. (2015) 'The Louvre Abu Dhabi: Prestige Project or Paradigm Shift?', http://www. artslant.com/la/articles/ show $/ 42007$

Macron, E. (2017). Attractiveness - United Arab Emirates/ inauguration of the Louvre Abu Dhabi - Speech by M. Emmanuel Macron, President of the Republic. 08.11.2017. http://www.worldaffairsjournal.org/content/macronspeech-opening-louvre-abu-dhabi adresinden 04.06.2018 tarihinde erişilmiştir.
Magelssen, S. (2007). Living history museum: Undoing history through performance. Lanham, Maryland: Scarecrow Press.

Malcolm, C. (2017). The History of Museums in the Emirates. https://www.thenational.ae/arts-culture/the-history-ofmuseums-in-the-emirates-1.43391 adresinden 11.05.2017 tarihinde erişilmiştir.

Malraux, A. (1956). Museum Without Walls. The Voices of Silence. UK: Secker\&Warburg.

Mason, R. (2006). Cultural theory and museum studies. In S. McDonald (Ed.). A companion to museum studies (pp.17-32). UK: Blackwell Publishing.

McClellan, A. (2012). Museum Expansion in the Twenty-First Century: Abu Dhabi. Journal of Curatorial Studies, 1(3): 271293.

McDonald, S. (1998). Exhibitions of power and powers of exhibition: an introduction to the politics of display. In S. McDonald (Ed.). The politics of display: Museums, signs, culture (pp.1-24). UK: Routledge.

Mejeher-Atassi, S.; Schwartz, P. J. (2012). Introduction. In S. Mejeher-Atassi and J.P. Schwartz, Eds. Archives, Museums and Collecting Practices in the Modern Arab World, pp.1-25. UK: Ashgate.

Mubarak, K. M. E. H.; Martinez, J. L. (2017). Louvre Abu Dhabi: Masterpieces of the collection. Abu Dhabi and Paris: SKIRA.

Mustafa, M. H. (2010). Tourism and Globalization in the Arab World, International Journal of Business and Social Science, 1(1), 37-49.

Nelson, C. (2004). UAE National Women at Work in the Private Sector: Conditions and Constraints. Labor Market Study, no:20. UAE: Centre for Labour Market Research \& Information (CLMRI).

Ouroussoff, N. (2010). Building Museums and Fresh Arab Identity. New York Times. https://www.nytimes. com/2010/11/27/arts/design/27museums.html adresinden 03.06.2018 tarihinde erişimiştir.

Picton, 0. (2010). Usage of the concept of culture and heritage in the United Arab Emirates- an analysis of Sharjah heritage area. Journal of Heritage Tourism, (5): 69-84.

Prager, L. (2015). Displaying Origins: Heritage Museums, Cultural Festivals, and National Imageries in the UAE. Horizons in Humanities and Social Sciences: An International Refereed Journal, 1 (1), 22-46.

Preziosi, D. (2011). Myhts of nationality: In S.J. Knell et al (Eds.). National museums - New studies from all around the world (pp.55-66). UK: Routledge.

Rojek, C. (1999). Fatal attractions. In D. Boswell, \& J. Evans (Eds.). Representing the nation: A reader: histories, heritage and museums (pp. 185-207). London / New York: Routledge.

Roppola, T. (2012). The Constructing Visitor Experience. In Designing for the Museum Visitor Experience (pp.57-75). US: Routledge. 
Shadid, A. (2012). An Ambitious Arab Capital Reaffirms Its Grand Cultural Vision. http://www.nytimes.com/2012/01/25/ world/middleeast/abu-dhabi-reaffirms-its-grand-plan-form u s e u m s.h t m l ? _ r = 1 \& p a g e w a n t e d = a l l adresinden10.08.2017 tarihinde erişilmiştir.

Simonet, D.; Vincent, C. (2014). The Management of Museums in Sharjah. In Public Administration and Policy in the Middle East, (ed. Alexander R. Dawoody), pp. 247-261. US: Springer.

Sylvester, C. (2009). Art/Museums: International Relations Where We Least Expect It. UK: Taylor\& Francis.

United Arab Emirates Ministry of Culture and Knowledge Development (2007). About Ministry. http://www.mcycd. gov.ae/sites/MCYCDVar/en-us/Pages/AboutTheMinistry. aspx adresinden 14.01.2016 tarihinde erişilmiştir.

United Nations, Department of Economic and Social Affairs (2017). Population Division. World Population Prospects: The 2017 Revision. https://esa.un.org/unpd/wpp/Graphs/ DemographicProfiles/ adresinden 19.07.2017 tarihinde erilişmiştir.

Üçağaç, A. (2015). Birleşik Arap Emirlikleri 2015, Ortadoğu Yıllığı 2015, 231-240.

Veldhuizen, A. (2017). Education Toolkit: Methods \& Technics from Museum and Heritage Education. Holland: CECA.

Vivant, E. (2011) 'Who brands whom? The role of local authorities in the branching of art museums', Town Planning Review, 82(1) 99-115.

Watson, S. (2007). Museums and their Communities. US: New York, Routledge.

World Tourism Organization (WTO) (2001). Tourism Highlights 2001 Edition.

World Tourism Organization (WTO) (2011). Tourism Highlights 2011 Edition.

World Tourism Organization (WTO) (2016). Tourism Highlights 2015 Edition.

Yıldırım, A. ve Şimşek, H. (2006). Sosyal Bilimlerde Nitel Araştırma Yöntemleri. Ankara: Seçkin Yayıncılık. 